\title{
Correspondence
}

\section{Inappropriate use of the oxygen flush to check an anaesthetic machine}

To the Editor:

I would like to comment on the case of "profound hypercapnia due to disconnection within an anaesthetic machine" reported by Berner. ${ }^{1}$ He notes that it is the anaesthetist's responsibility to check his equipment, especially the low-pressure segment of the anaesthesia system, for patency and leaks. The Foex-Crampton Smith manceuvre ${ }^{2}$ with the Ghani ${ }^{3}$ modification is described and noted to be the most satisfactory method of assessing the integrity of the gas line from the flow meters through to the patient end of a Bain circuit. I would agree that this manoeuvre is valuable, but I would like to emphasize that the oxygen flush valve is often used inappropriately, as it was in this case, in the pre-anaesthetic check of the machine. The reservoir bag was filled and the system was pressurized using the "oxygen flush bypass." However, this method of testing does not verify the integrity of the anaesthetic machine low-pressure gas circuitry. The ability to fill the reservoir bag and to generate positive pressure in the circuit (and thus ventilate the patient) must always be confirmed using normal or low flows from the rotameter flowmeters, not flow from the oxygen flush which is a separate high pressure line. This principle should be applied regardless of the type of circuit used, since it is possible to have no fresh gas flow from the flowmeters, and still be able to pressurize the breathing system normally from the oxygen flush valve.

Comm and Rendell-Baker ${ }^{4}$ reported a case in 1982 in which a complete disconnection was encountered at the same site on the anaesthetic machine as Berner experienced. The diagram in their article graphically illustrates this identical problem. The metal tubing which conveys the gases to the common gas outlet had been left disconnected after servicing. However, an oxygen analyzer and a mass spectrometer wamed of the problem shortly after the case began. The breathing system in this case had also been pressurized using the oxygen flush valve. On reviewing their experience, the following observations were made: (1) There was a check valve between the vaporizers and the common gas outlet. (2) Oxygen from the oxygen flush comes directly from the reducing valves or the pipeline supply, bypassing the flowmeter and vaporizer. The rise in pressure in the breathing system from the oxygen flush closed the check valve, thus preventing escape of gas and discovery of the leak. Comm and Rendell-Baker recommended that "the gas tightness of the machine's internal system should be checked simultaneously with the breathing system by setting a two-liter flow on the oxygen flowmeter before the system is filled with the oxygen flush."

Dorsch and Dorsch" ${ }^{5}$ also state that "testing for leaks by pressurizing the breathing system frequently will not detect leaks in the machine. Most machines are equipped with unidirectional check valves, either near the common outlet or in a vaporizer, to prevent pressures in the breathing system from affecting the accuracy of the flow meters or vaporizers. Testing the breathing system for leaks by pressurizing will reveal only leaks downstream of these check valves. Important leaks such as those associated with flowmeters may go undetected." Dorsch and Dorsch recommended that the machine be checked for leaks separately from the breathing system, and they describe a method of doing so using gas from the flowmeters and a pressure gauge.

Caplan ${ }^{6}$ reported a case in 1980 of a total disconnection between the flowmeters and an Ethrane vaporizer, with littlc apparent change in tidal volume. A Drager respirator with hanging betlows and a circle system were used. The bellows in ventilators of the "hanging bellows" type usually returns to its pre-inspiratory position by gravity. Thus, tidal volume and breath sounds appear normal even when no fresh gas is being added to the circuit ( $\mathrm{a}$ "hanging bellows" ventilator was also used in Bemer's case). In contrast, a ventilator with an "ascending bellows" will collapse or partially collapse when the fresh gas flow is reduced below a certain level, thus alerting the anaesthetist to the problem.

A fully checked and normally functioning anaesthetic machine at the beginning of the case does not guarantee that it will remain so throughout the case. I look forward to the day when every anaesthetic machine has an $\mathrm{O}_{2}$ analyzer downstream from the common gas outlet, a capnograph and $\mathrm{O}_{2}$ saturation monitor.

In summary, the oxygen flush valve continues to be inappropriately used in the pre-anaesthetic check of the gas machine. This method of testing may not identify even complete disconnects in the low pressure gas 
circuitry. The oxygen flush valve must not be used to verify the integrity of the anaesthetic machine low pressure gas circuitry.

\section{Bruce $G$. Dodgson MD FRCPC}

Department of Anaesthesia

The Hospital for Sick Children

555 University Avenue

Toronto, Ontario M5G IX8

\section{ACKNOWLEDGEMENT}

Thanks to Dr. R.E. Creighton and Dr. J. Lerman for their suggestions.

\section{REFERENCES}

1 Berner MS. Profound hypercapnia due to disconnection within an anaesthetic machine. Can J Anaesth 1987; 34: 622-6.

2 Foex P, Crampton Smith A. The Foex-Crampton Smith manoeuvre (letter). Anaesthesia 1977; 32: 294.

3 Ghani $G$. Safety check for the Bain circuit (letter). Can Anaesth Soc J 1984; 31: 487.

4 Comm $G$, Rendell-Baker $L$. Back pressure check valves a hazard. Anesthesiology 1982; 56: 327-8.

5 Dorsch $J A$, Dorsch SE. Understanding Anesthesia Equipment. 2nd. edition Baltimore: Williams \& Wilkins 1984, pp. 402-3.

6 Caplan L, Ramanathan S, Chalon $J, O^{\prime}$ Meara JB, Turndoff $H$. A possible hazard with use of the Ohio ethrane vaporizer. Anesth Analg 1980; 59: 65-8.

\section{Detecting disconnections within anaesthetic machines}

\section{To the Editor:}

I was very interested in the report of the hidden disconneetion of an anacsthetic machine common gas line downstream from the vaporizers. ${ }^{1}$ We experienced a similar disconnection several years ago following a change of vaporizers by hospital staff. The anaesthetist involved had no knowledge of this maintenance activity. The disconnection was hidden behind a suction control device mounted on the gas machine (an Ohio 30/70 Proportioner model).

In our case, the leak was not suspected for well over an hour. Despite severe hypercarbia and hypoxia $\left(\mathrm{PaO}_{2}\right.$ $28 \mathrm{mmHg}$ or $3.2 \mathrm{kPa}$ ), the patient had no neurologic sequelae and, even more surprising, had no recall of the surgical procedure.

We undertook a critical-incident review following our near-disastrous mishap in North Bay. Several important discoveries were made that are not emphasized in Berner's case report.

First, this occurrence was reported in 1982 by Comm and Rendell-Baker. ${ }^{2}$ The machine in their case was an Ohio Omnitrol model. These authors emphasized that the presence of a one-way (or "check") valve between the fresh gas outlet and the vaporizers is the important factor in this type of incident. The patient circuit can be airtight after pressurization by the oxygen flush despite a large leak upstream of the one-way valve.

Tests which can detect this are mentioned in the article (the Ohio negative pressure leak test or "bobbin bounce") but there is another test which can be done. The circuit is first pressurized to $30 \mathrm{~cm} \mathrm{H}_{2} \mathrm{O}$ with the rotameters off. After confirming the patient circuit is leak-free, the axygen flowmeter is turned on. If the circuit is intact upstream of the one-way valve, the patient circuit pressure will increase above $30 \mathrm{~cm} \mathrm{H} \mathrm{H}_{2} \mathrm{O}$. If a leak of greater than $3 \mathrm{~L} \cdot \mathrm{min}^{-1}$ at $30 \mathrm{~cm} \mathrm{H}_{2} \mathrm{O}$ pressure is present, no increase in patient circuit pressure will be noted.

Another factor of significance is that Bemer was using a "hanging bellows" type ventilator. A "floating bellows" ventilator will not create a negative pressure in the patient circuit and therefore no room ait will be sucked into the circuit. The floating bellows would slowly collapse in this situation and the anaesthetist would be alerted to a problem much earlier.

Following our critical incident review in North Bay, we decided on the following steps to prevent future similar accidents:

1 A large sign is placed on any anaesthetic machine following any servicing so the anaesthetist is aware that he or she is the first to use the gas machine. This results in a higher index of suspicion for machine faults if there are intraoperative difficulties.

2 Anaesthetists are now all aware of pre-anaesthetic tests required in addition to simple tests of patient circuit integrity (e.g., negative pressure bulb tests and tests of fresh gas flow into a pressurized patient circuit).

3 The suction control devices are now installed behind the piping for the fresh gas flow.

4 A patient circuit oxygen concentration monitor is now in place on each gas machine (in addition to the proportioner valve).

5 All patients undergoing general anaesthesia are now monitored by pulse oximetry.

6 All new ventilators purchased by our department will be of the floating bellows type with built-in low pressure alarms.

A.O. Davies MD FRCRC

1140 Glenwood Road

North Bay, Ontario P1B 4S5 